I Universidade Federal do Rio de Janeiro (UFRJ), Programa de

Pós-Graduação em Serviço Social, Rio de Janeiro, RJ, Brasil

ksemello@gmail.com

https://orcid.org/oooo-ooor-6683-4444

Kátia Sento Sé Mello'

\title{
UM DIÁLOGO INACABADO ENTRE A SOCIOLOGIA E A PSICOLOGIA
}

Mauss, Marcel. (2018).

Relações reais e práticas entre a psicologia e a

sociologia. Org. e ed. Marcia Consolim, Noemi

Pizarroso López e Raquel Weiss. Edição bilíngue

e crítica. São Paulo: Edusp.

A Edusp traz a publicação de Relações reais e práticas entre a psicologia e a sociologia em versão original e bilíngue da conferência de Marcel Mauss proferida em ro de janeiro de I924, na ocasião em que assumiu a presidência anual da Sociedade de Psicologia na França. No mesmo ano Mauss fundou o Instituto Francês de Sociologia com o objetivo de manter a revista L'Anée Sociologique. Trata-se, portanto, de um esforço que, juntamente com instituições de diversos países, pretende promover uma reflexão crítica sobre a Escola Sociológica Francesa.

Os organizadores dessa publicação buscaram contextualizar as ideias de Mauss sobre o tema, centradas sobretudo nas disputas político-institucionais entre sociólogos e psicólogos das instituições francesas de então, mais do que reforçar o estigma de que nosso etnólogo era um "durkheimiano heterodoxo", como o fez Lévi-Strauss (I974) em sua introdução à obra Sociologia e antropologia publicada originalmente em I950. A Academia Francesa de Sociologia havia sofrido forte impacto na redução dos seus quadros, resultante da participação de muitos sociólogos na Primeira Guerra Mundial. E Durkheim, que havia consolidado a escola de sociologia, também morre em I9I7. O aceite de Mauss ao convite de Ignace Meyerson revela um estreito diálogo intelectual, bem como laços afetivos entre ambos e entre Mauss e diversos psicólogos da época. Os documentos apresentados na publicação revelam ainda um diálogo amistoso entre psicólogos e sociólogos, que se sobrepõe às disputas institucionais. 
A publicação apresenta um corpus documental constituído por um dossiê crítico com a participação de diversos pesquisadores que se debruçam sobre os estudos da Escola Sociológica Francesa. Em anexo, correspondências inéditas de Mauss revelam profícua troca intelectual entre ele e diversos psicólogos da época. Além disso, a publicação agrega resenhas e artigos críticos de seus interlocutores após a conferência de I924. E, por fim, há diversos textos de Mauss que complementam sua proposta desenvolvida na conferência.

A preocupação de Marcel Mauss na conferência "Relações reais e práticas entre a psicologia e a sociologia" reside em fazer um balanço entre os dois campos de saber. Ele parte do princípio de que, de um lado, a psicologia se desligou da filosofia e, de outro, a sociologia da metafísica. Afirma que ambas as ciências são da ordem da fenomenologia e constituídas, de um lado, pelo reino da consciência e, de outro, pelo da consciência coletiva, sendo separadas por "questões de medida e de fatos". Mauss dirige-se à plateia indagando-se sobre as relações desejáveis entre os dois grupos de cientistas, as colaborações que deveriam ser estimuladas e os conflitos que deveriam ser evitados.

Uma segunda orientação de sua conferência diz respeito a quais ques tões levantadas pela psicologia poderiam ser respondidas pela sociologia e vice-versa. Partindo do diálogo com a antropologia, Mauss afirma que a sociologia considera o homem um "ser vivo, consciente e sociável”. Segundo ele, a sociologia registra somente os fatos humanos, e o que distingue as sociedades animais não humanas das sociedades humanas é que nas primeiras não observamos a pressão da consciência de uns sobre a dos outros. Nas primeiras também estão ausentes práticas estéticas e religiosas, ou seja, instituições sociais, que distinguem a vida comum em sociedade.

Mauss sustenta que a diferença fundamental entre os dois campos de saber é que a psicologia estuda os fatos da consciência observados no comportamento individual enquanto a sociologia estuda os fatos da consciência coletiva e aquilo que denomina "o arbitrário", "a sugestão exterior", enfim, o simbólico ou, em suas palavras, "a obrigação moral”.

$\mathrm{Na}$ época, Mauss destacava três pontos no estudo da sociologia. Os fenômenos morfológicos, aqueles classificados e quantificados pelos homens. Os fenômenos ligados ao funcionamento das sociedades, quando as representações coletivas adquirem aspectos mensuráveis, pertencentes à fisiologia. Os fenômenos vinculados à tradição e à linguagem, tratados pela historicidade. Com relação aos fenômenos fisiológicos, ou que se relacionam às representações coletivas, Mauss argumenta que os psicólogos podem auxiliar a sociologia. É a área que denominou "psicologia coletiva". O autor acrescenta, ainda, que os elementos da psicologia imprescindíveis para a sociologia se referem ao estudo da consciência e suas relações com o corpo. Dessa forma, salienta a noção de vigor mental, quando enfatiza a con- 
tribuição das análises sobre indivíduo e sociedade provenientes das sociedades da Polinésia e Austrália, onde os indivíduos que acreditavam ser enfeitiçados deixavam-se morrer. Destaca os estudos de Durkheim em As formas elementares da vida religiosa e sua própria experiência na guerra, quando afirma que conheceu "a força física e mental decorrente de se ter os nervos no lugar". Com a noção de psicose, constrói sua hipótese de que certas ideias se manifestam na imaginação e provêm não de outras ideias, mas do que chama de instintos mais profundos.

Para Mauss, a loucura, o culto funerário, a vingança em grupo, as mitologias, entre outras manifestações, tornaram-se compreensíveis a partir das observações de noções caras à psicologia. A noção de símbolo, presente em trabalhos pioneiros de Durkheim sobre a religião e o direito, permite a comunhão e a comunicação entre os homens em sociedade que, sendo signos exteriores aos estados mentais, são permanentes, sucessivos e tomados como realidades. Gritos e palavras, gestos e ritos são, para Mauss, traduções dos símbolos da "etiqueta e da moral" e traduzem a presença do grupo, mas exprimem, igualmente, as ações e as reações do que denomina instintos dos membros de um grupo. Um dos caros exemplos por ele citado diz respeito ao tabu que, na Polinésia e África do Norte, proíbe um indivíduo de passar sua sombra sobre outro. Argumenta que esse tabu "manifesta o instinto de uma forte personalidade que protege em torno dela algo como uma esfera e, ao mesmo tempo, o res- peito que as demais têm por ela. $\mathrm{Ou}$ seja, esse rito negativo é apenas o símbolo das relações entre os instintos de uns e os instintos de outros..." (p. 7I). Quanto às contribuições da sociologia à psicologia, Mauss realiza quase uma conclamação:

será que podemos, nós, sociólogos,
pedir-vos, para nosso próprio bem e
para o bem comum a todos nós, que
aceiteis trabalhar ainda mais em vos-
so campo normal, em vosso domínio,
desbravado pelos psicopatologistas, do
estudo do homem completo, e não
compartimentado? É esse homem, es-
se ser indivisível - ponderável, mas
seccionável que encontramos em nos-
sas estatísticas morais, econômicas e
demográficas (p. 79).

Destaca, ainda, casos etnográficos entre os Maori e Malaio nos quais a tendência à vingança e à morte não são estados anormais da vida social ou individual como poderia preconizar a psicologia de então. Trata-se do social, melhor dizendo, do que considera o fato comum a todos que dele participam e, sendo comum, despe-se das características individuais.

A leitura da conferência e a observação dos documentos e textos inseridos na nova publicação parecem revelar que, apesar de a psicanálise já estar estabelecida desde I900 com a publicação de Interpretação dos sonhos, de Freud (2019), Marcel Mauss e os pesquisadores contemporâneos da Escola Sociológica Francesa não ampliaram o diálogo da sociologia com essa "ciência do inconsciente". Apesar do debate frutífero que Freud e, posteriormente, Lacan trazem para o público a respeito da relação entre o 
individual e o social, Mauss não faz referência a qualquer possível diálogo com a psicanálise. É verdade que a receptividade da psicanálise na França teve lugar dois anos depois da conferência de Mauss. Originalmente ocorreu em especial nas províncias francesas, enquanto em Paris permanecia ligada, de um lado, ao contexto intelectual dos meios literários com Charles Baudelaire e Arthur Rimbaud, contexto esse que pretendia denunciar a aspiração individual burguesa daqueles tempos (Machado, Sousa e Rodrigues, 20I7). De outro lado, aparecia muito ligada à medicina e à ideia do "tratamento" dos transtornos psíquicos. Ainda assim, em I9I3, Freud (20I2) já havia publicado o livro Totem e tabu, no qual declara que o sujeito coletivo é também o sujeito do individual. Inspirado em mitos caros aos estudos antropológicos, Freud demonstra o quanto o simbólico se encontra atravessado pelos domínios psíquicos e sociais. Dessa forma, dos de neurologistas franceses e psiquiatras alemães, correntes em face das quais o pai da psicanálise construiu, de forma subversiva, a teoria do inconsciente.

O que Mauss denomina "tanatomania”, por exemplo, presente em sociedades polinésias e melanésias, está diretamente relacionado ao trabalho de Freud a respeito da pulsão de morte. Apesar disso, nosso sociólogo/etnólogo não a leva em toda consequência. E chama de excessos as interpretações propostas por Freud. Ele acaba, no entanto, não fugindo da ideia de uma espécie de movimento pulsional do psiquismo que explica a tensão entre pulsões de vida e de morte. O conceito trieb, utilizado por Freud, traduzido em francês por l'instinct e em português por instinto, deixa Mauss ainda no ramo da espécie animal. A palavra na língua alemã refere-se à pulsão, realidade psíquica que somente os homens, como seres de linguagem, têm. Tal resistência ao diálogo com a psicanálise parece ter impedido - e ainda impede - um frutífero diálogo entre esses campos de saber. Levar esse diálogo às últimas consequências parece retomar a proposta de Freud (2019, I990), que já aparecia em A interpretação dos Sonhos e Sobre a psicopatologia da vida cotidiana, ou seja, as possibilidades da psicanálise como método que pode ser aplicado a várias dimensões da produção humana e não apenas à clínica.

Recebida em 26/03/2020 | Aprovada em 21/07/2020 


\section{REFERÊNCIAS BIBLIOGRÁFICAS}

Freud, Sigmund. (2019) [1900]. A interpretação dos sonhos. In: Obras completas. Trad. Paulo César de Souza. São Paulo: Companhia das Letras.

Freud, Sigmund. (20I2) [I9I2-I9I4] Totem e tabu, contribuição à história do movimento psicanalítico e outros textos. In: Obras completas. São Paulo: Companhia das Letras.
Freud, Sigmund. (I990) [I90I]. Sobre a psicopatologia da vida cotidiana. In: Edição Standard brasileira das obras psicológicas completas de Sigmund Freud, v. 6. Rio de Janeiro: Imago. Disponível em: <http:// conexoesclinicas.com.br/wp-content/ uploads/20I5/or/freud-sigmundobras-completas-imago-vol-o6-I9oI. pdf $>$. Acesso em fev. 2020.

Lévi-Strauss, Claude. (I974). Introdução. In: Sociologia e antropologia. São Paulo: EPU.

Machado, Letícia Vier; Sousa, Fernando Aguiar B. \& Rodrigues, Adriana. (20I7). Novo século, antigo mal-estar: uma história recente da psicanálise na França. Revista Subjetividades, I7/I, p. $55-67$.

Kátia Sento Sé Mello é doutora em antropologia pelo PPGA/ UFF, mestre pelo PPGSA/UFRJ, professora do Programa de Pós-Graduação em Serviço Social da ESS/UFRJ, líder do Grupo Sociabilidades Urbanas, Espaço Público e Mediação de Conflitos (GPESEM/CNPq), pesquisadora do Necvu/UFRJ e do INCT-Ineac-Nepeac/UFF. Experiência e publicações nas áreas de antropologia do direito, administração e mediação de conflitos, políticas públicas de segurança. Área mais recente de pesquisa: sistema prisional brasileiro com ênfase no encarceramento de mulheres. Último livro publicado: Administração de conflitos, espaço público, sociabilidades urbanas em perspectiva comparada. 